\title{
Alendronate treatment alters bone tissues at multiple structural levels in healthy canine cortical bone
}

\author{
Claire Acevedo $^{\mathrm{a}, \mathrm{b}}$, Hrishikesh Bale ${ }^{\mathrm{b}}$, Bernd Gludovatz ${ }^{\mathrm{a}}$, Amy Wat ${ }^{\mathrm{b}}$, Simon Y. Tang ${ }^{\mathrm{c}}$, \\ Mingyue Wang ${ }^{d}$, Björn Busse ${ }^{e}$, Elizabeth A. Zimmermann ${ }^{e}$, Eric Schaible ${ }^{a}$, \\ Matthew R. Allen ${ }^{\mathrm{f}}$, David B. Burr ${ }^{\mathrm{f}, \mathrm{g}}$ and Robert O. Ritchie ${ }^{\mathrm{a}, \mathrm{b}^{*}}$ \\ ${ }^{a}$ Materials Sciences Division, Lawrence Berkeley National Laboratory, Berkeley, CA 94720, \\ USA \\ ${ }^{\mathrm{b}}$ Department of Materials Science and Engineering, University of California Berkeley, CA \\ 94720, USA
}

${ }^{c}$ Department of Orthopaedic Surgery, School of Medicine, Washington University, St Louis, MO 63110, USA

${ }^{\mathrm{d}}$ International Research Center for Advanced Structural and Bio-Materials, Beihang University, Beijing 100083, China

${ }^{\mathrm{e}}$ Department of Osteology and Biomechanics, University Medical Center Hamburg, D-22529 Hamburg, Germany

${ }^{\mathrm{f}}$ Department of Anatomy and Cell Biology, Indiana University School of Medicine, Indianapolis, IN 46202, USA

${ }^{\mathrm{g}}$ Department of Biomedical Engineering, Indiana University-Purdue University, Indianapolis (IUPUI), Indianapolis, IN 46202

* corresponding author: roritchie@lbl.gov 


\begin{abstract}
Bisphosphonates are widely used to treat osteoporosis, but have been associated with atypical femoral fractures (AFFs) in the long term, which raises a critical health problem for the aging population. Several clinical studies have suggested that the occurrence of AFFs may be related to the bisphosphonate-induced changes of bone turnover, but large discrepancies in the results of these studies indicates that the salient mechanisms responsible for any loss in fracture resistance are still unclear. Here the role of bisphosphonates is examined in terms of the potential deterioration in fracture resistance resulting from both intrinsic (plasticity) and extrinsic (shielding) toughening mechanisms, which operate over a wide range of length-scales. Specifically, we compare the mechanical properties of two groups of humeri from healthy beagles, one control group comprising eight females (oral doses of saline vehicle, $1 \mathrm{~mL} / \mathrm{kg} / \mathrm{day}, 3$ years) and one treated group comprising nine females (oral doses of alendronate used to treat osteoporosis, $\quad 0.2 \mathrm{mg} / \mathrm{kg} /$ day, 3 years). Our data demonstrate treatment-specific reorganization of bone tissue identified at multiple length-scales mainly through advanced synchrotron $\mathrm{x}$-ray experiments. We confirm that bisphosphonate treatments can increase non-enzymatic collagen cross-linking at molecular scales, which critically restricts plasticity associated with fibrillar sliding, and hence intrinsic toughening, at nanoscales. We also observe changes in the intracortical architecture of treated bone at microscales, with partial filling of the Haversian canals and reduction of osteon number. We hypothesize that the reduced plasticity associated with BP treatments may induce an increase in microcrack accumulation and growth under cyclic daily loadings, and potentially increase the susceptibility of cortical bone to atypical (fatigue-like) fractures.
\end{abstract}

Keywords: Anti-resorptives; Bisphosphonates; Fracture prevention; Fracture toughness; Osteoporosis 


\section{Introduction}

More than 200 million prescriptions have been dispensed worldwide for oral bisphosphonates (BPs) [1] since the first bisphosphonate approved for treatment of osteoporosis, alendronate, was introduced into the market in 1995. Indeed, bisphosphonate treatments for osteoporosis have been definitively associated with reduced fracture risk [2]. However, long-term adverse effects of the treatment started to emerge in 2005, specifically with atypical femoral fractures [3-6], osteonecrosis of the jaw [7] and esophageal cancer [8,9] all being reported for long-term users of BPs. With a rate of atypical femoral fractures (AFFs) of about 1/1000 per year for a patient on bisphosphonate, the incidence of AFFs remains low compared to the reduction in incidence of any fracture occurring under bisphosphonate treatment, rated at 15/1000 per year [10]; however, the morbidity is high with AFFs because of the catastrophic nature of the fracture and delayed healing. These considerations potentially pose critical health problems for the aging population, which prompted the American Society for Bone and Mineral Research (ASBMR) to appoint a Task Force to conduct a major review on AFFs [6,11]. In response to this review, the Food and Drug Administration in 2010 required a warning label for bisphosphonates indicating the potential risk for AFFs and mandated further investigation into bisphosphonate-associated problems.

Reducing fracture risk and maintaining bone quality is of utmost importance to bone health in aging, osteoporosis, and treatments for bone disease. Bone derives its unique stiffness, strength and toughness from its hierarchical arrangement of characteristic structural features spanning molecular to macroscopic length-scales. Indeed, fracture resistance in general originates at multiple length-scales; at nanoscale dimensions, intrinsic toughening mechanisms resist the initiation and growth of cracks primarily via plasticity acting ahead of a growing crack, whereas at 
microscale dimensions, extrinsic toughness mechanisms act to impede the crack growth primarily by crack-tip shielding from crack deflection and bridging [12].

Studies addressing the mechanical properties of bisphosphonate-treated bone suggest that suppressing bone turnover decreases fracture risk by improving bone mass, i.e., bone quantity. Although the majority of this work has been performed on trabecular bone, the site-specific nature of bisphosphonates and the emergence of atypical femur fractures have changed the focus of bisphosphonate research towards cortical regions. Indeed, in cortical bone, the major concern is that suppression of remodeling associated with long-term bisphosphonate use could have detrimental effects on cortical bone quality and toughness at microscopic and submicroscopic levels [13].

Long-term bisphosphonate use could have measurable effects on cortical bone structure and mechanical properties at multiple length-scales. At microscales, where extrinsic toughening in cortical bone primarily involves crack deflection† at the boundaries ("cement lines") of the osteons (i.e., longitudinal structures with a central Haversian canal consisting of a blood vessel and nerves), BPs have a tendency to change the mineralization of the matrix. Treated bone tissue from femoral cortical cross-sections have shown a reduced heterogeneity of mineralization $[14,15]$ as well as treated iliac crest tissue in healthy postmenopausal women [16], which could affect fracture risk and correspondingly reduce the contribution to fracture resistance from extrinsic toughening leading to easier crack propagation [13,17-19].

At the nanoscale level, collagen molecules and nanocrystal platelets are the basic building blocks forming mineralized collagen fibrils of bone. Fibrils are arranged in arrays and

\footnotetext{
$\dagger$ Whereas microcrack formation and consequent crack deflection at the osteonal structures provides the primary mechanism of (extrinsic) toughening for cracks in bone propagating in the transverse direction, for cracking in the longitudinal (splitting) direction, the intact regions between these microcracks can act as "uncracked ligament" bridges across the crack surfaces; these features further provide extrinsic toughening by carrying load that would otherwise be used to further propagate the crack, e.g., refs. [19,20].
} 
organized in fiber patterns comprising the lamellar structure of the osteons. At this level, fibrillar sliding at the interface between mineralized collagen fibrils and the extrafibrillar matrix represents a major source of plasticity in bone; it is an intrinsic toughening mechanism that promotes energy dissipation and forms plastic zones ahead of a growing crack, thereby blunting the tip of any growing cracks. As an unintended consequence of the decrease in bone remodeling, anti-resorptive agents also increase the proportion of advanced glycation end products (AGEs), which have been shown to non-enzymatically cross-link collagen and to reduce post-yield properties and toughness of bone by altering the formation and propagation of microdamage [21,22].

A better understanding of the effects of long-term bisphosphonate use on fracture resistance could provide clues as to whether bisphosphonates are directly linked to AFFs. The incidence of AFF cases is quite small, which makes it difficult to identify whether they are primarily associated with untreated or BP-treated patients [23-26] or whether BPs increase the risk for AFFs $[6,11,27,28]$. Thus, the prime concern of this study is to better understand whether BPs cause changes to the bone structure that could make the bone more susceptible to atypical femoral fracture. Indeed, AFFs associated with bisphosphonate use are thought to be insufficiency stress fractures, i.e., a type of fatigue fracture caused by repeated daily loading of bone tissue. AFFs present a unique pattern of transverse or short oblique fracture with a smooth fracture surface, commonly seen in fatigue fractures [29]. Recent studies suggest that more homogeneity of the bone-matrix may be a possible explanation in the case of AFFs $[13,18]$, where less deflected crack paths would result in the reported smoother fracture surfaces.

The animals examined here were already extensively studied by Burr and co-workers [22,3032] to document changes associated with $\mathrm{BP}$ treatment in bone from dogs, which present similarities with human bone in their intra-cortical remodeling rates. Mechanical properties were 
reported in canines following 1 or 3 years of alendronate treatment at clinical doses (for postmenopausal osteoporosis) or high doses (five time greater than the clinical dose). Long-term (3 years) alendronate treatment was shown to reduce the work-to-fracture (toughness) in ribs and vertebrae $[30,31]$ by nearly $30 \%$ at a clinical dose without significantly affecting the elastic properties of the material. Suppression of bone turnover increases the mineral content and the collagen maturity in trabecular bone [33]. Reports on cortical bone from femurs and tibiae of these animals concluded that no significant differences were found in femoral mechanical properties even at high doses [32] whereas in tibiae, post-yield work-to-fracture was significantly reduced in cortical bone at high doses (not at clinical doses) compared to control after just one year of treatment [22]. BPs are likely to affect more significantly, and in a shorter period of time, bone properties in trabecular bone where bone turnover is higher compared to cortical bone.

The novelty of this study lies in the combination of multiple high-resolution mechanical and structural characterizations to assess the effect of alendronate treatment across the complex multidimensional structure of cortical bone ranging from molecular to micro levels. Humeri were chosen to perform this study because, in the absence of femurs to tests, this long bone in dogs is the most similar to the femur in terms of work to fracture and cross-sectional shape [34].

Understanding the effects of bisphosphonates on cortical bone quality and fracture risk are critical issues in bone health, which should improve our understanding of atypical fractures. As studies have yet to determine the effects of long-term bisphosphonate treatments on the structural and mechanical quality of cortical bone across multiple length-scales, our intent in this study was to isolate the effects of bisphosphonates from that of osteoporosis which is well known to decrease the resistance of bone to fracture. Here we investigate the effect of BPs on cortical bone from the humeri of skeletally mature beagle dogs that do not have osteoporosis - 
thus separating the effects of BPs from those of underlying skeletal disease. The goal of this paper is not to trigger AFF since we are working with bone from healthy young dogs but to understand the potential effects and participation of BPs on the deterioration of bone quality that might contribute to AFFs in BP-treated osteoporotic bone under daily fatigue loadings. We use advanced x-ray synchrotron instrumentation, specifically involving computed tomography and small-/wide-angle $\mathrm{x}$-ray scattering/diffraction to examine the mechanical properties at multiple length-scales in uniform groups of control dogs and dogs treated with alendronate doses typically given to osteoporotic women. Our data reveal the reorganization of canine bone tissue following BP treatment with corresponding effects on bone toughness, principally originating from changes in the collagen environment affecting bone plasticity at different structural levels and changes in osteonal density and size of the Haversian canals.

\section{Materials and Methods}

\section{Study design}

An analytic experimental study was used to quantify the potential effects of longterm BPs on bone quality. To this end, bone characterization is compared at multiple hierarchical levels between two parallel groups (two independent variables): a control group treated for 3 years with oral doses of saline vehicle $(1 \mathrm{~mL} / \mathrm{kg} / \mathrm{day})$ and a BP-treated group treated for 3 years with daily oral doses of alendronate corresponding to the doses used to treat osteoporotic women $(0.2 \mathrm{mg} / \mathrm{kg} /$ day) (see experimental details in ref. [31]). The sample comprises canine bones from 8 control and 9 BP-treated animals. Different sets of specimens were created for each type of experiments, as described in the following sections.

\section{Animals}


Humeri of healthy, 4-5 year old, female beagle dogs (8 control and 9 BP-treated) were machined into cortical bone beam specimens; the same animals have been the source of several recent studies focused on BP-treated rib and vertebrae [30,31] as well as femoral and tibial cortical bone [32,22]. At sacrifice (between 2003 and 2005), bones with their surrounding musculature and soft tissues were wrapped in saline soaked gauze, sealed in plastic bags and stored at $-20^{\circ} \mathrm{C}$. After sectioning the frozen bone and during all stages of bone preparation, specimens were kept hydrated in saline solution.

\section{Mechanical and toughness testing}

To quantify the flexural strength properties of the control and alendronate-treated bone at the macroscale, we tested unnotched samples from the midshaft cortical bone which we loaded in three-point bending ( 8 control and 9 treated samples). Bone beam samples, $15 \mathrm{~mm} \mathrm{long}$, cut with a low-speed diamond saw along the longitudinal axis of humeri, were ground and polished under constant irrigation to final thickness of $\sim 0.75 \mathrm{~mm}$ and width of $\sim 1.75 \mathrm{~mm}$ in width. The longitudinal-oriented samples were soaked in $25^{\circ} \mathrm{C}$ Hanks' Balanced Salt Solution (HBSS) for at least $12 \mathrm{~h}$ prior to testing, and then tested in general accordance with ASTM D790 [35] under displacement control at $0.05 \mathrm{~mm} / \mathrm{min}$, with a loading span of $12 \mathrm{~mm}$, using a Microtest $2-\mathrm{kN}$ stage (Deben UK), with data recorded every $100 \mathrm{~ms}$.

The Young's modulus $E$ values were determined using nanoindentation. Irrigated samples (6 control and 6 BP-treated) were sectioned perpendicular to the bone's long axis using a lowspeed saw and then ground and polished with a $0.05 \mu \mathrm{m}$ diamond slurry. Between 27 and 36 nanoindentations were carried out on each fully hydrated sample using a TI 900 TriboIndenter Nanoindenter (Hysitron, Minneapolis, MN, USA) with a diamond Berkovich three-sided pyramid tip. The samples were tested with a peak load of $4 \mathrm{mN}$ at a loading rate of 800 

performed with a minimum distance of $13 \mu \mathrm{m}$ from each other and any Haversian canals to avoid any effects from them. Indentations were made in cross-section along the medial-lateral axis, extending from the endosteal to the periosteal surfaces of the diaphysis to account for possible variations in mechanical properties throughout the cortex thickness. For each location, the hardness was measured as the maximal force divided by the indentation area, and true elastic modulus was calculated from the reduced modulus using the Oliver-Pharr model [37]. The reduced modulus was computed using data along the unloading portion of the applied load. During unloading, the stiffness value is obtained as a function of the measured displacement and the applied force: $S=\mathrm{d} P / \mathrm{d} h$ where $S$ is the stiffness, $P$ is the pressure, and $h$ is the contact depth. The pressure was found using the load applied on the tip divided by a predetermined tip area function. The reduced modulus is proportional to the measured stiffness: $E_{\mathrm{r}}=k S / \sqrt{ } A_{\mathrm{h}}$ where $k$ is a constant related to the tip geometry and $A_{\mathrm{h}}$ is the predetermined tip area function. The Young's modulus was calculated from the reduced modulus for each indent using the relation: $1 / E_{\mathrm{r}}=\left(1-v^{2}\right) / E+\left(1-v_{\mathrm{i}}^{2}\right) / E_{\mathrm{i}}$, where $v$, the Poisson's ratio of the bone, is $0.3, v_{\mathrm{i}}$ and $E_{\mathrm{i}}$ are, respectively, the Poisson's ratio and Young's modulus of the indenter. The Young's modulus of each sample was calculated as an average of the Young's modulus of each indent on the sample.

To evaluate bone toughness, $12 \mathrm{~mm}$ long beam samples (3 control and 2 BP-treated) were prepared in similar manner as those for three-point bending although these samples had a width $W$ of $\sim 2 \mathrm{~mm}$ and thickness $B$ of $\sim 1 \mathrm{~mm}$, aligned along the long axis of the bone

\footnotetext{
*For such indentation measurements, a $60 \mathrm{~s}$ hold period was applied in ref. [36] after unloading the sample at $10 \%$ of maximum load to take into account any effects of thermal drift. In light of this work, we repeated our measurements for both bone groups with different holding times at maximum load to check for such creep effects, specifically with $120 \mathrm{~s}$ and $240 \mathrm{~s}$ hold times. No evidence was found of changes in the load or penetration depths for hold times between 10 and $240 \mathrm{~s}$.
} 
(longitudinal orientation). The beams were polished to $0.05 \mu \mathrm{m}$ finish to allow imaging of the bone-matrix microstructure during in situ testing and subsequently notched on the endosteum side in the transverse direction perpendicular to the bone's longitudinal axis. The notch was cut using a low-speed saw and sharpened (by polishing) with a razor blade irrigated with a $0.05 \mu \mathrm{m}$ diamond suspension (razor micro-notching) to achieve an initial crack size of roughly $1 \mathrm{~mm}$ with a $\sim 5 \mu \mathrm{m}$ root radius. Fracture toughness tests were performed in general accordance with ASTM E1820 recommendations [38] in three-point bending ( $8 \mathrm{~mm}$ loading span) on HBSS-soaked samples at $25^{\circ} \mathrm{C}$ under displacement control (at $0.033 \mathrm{~mm} / \mathrm{min}$ ) using the Microtest 2-kN stage mounted in a Hitachi S-4300SE/N variable pressure scanning electron microscope (SEM) under low vacuum conditions at $35 \mathrm{~Pa}$ and $25 \mathrm{kV}$; this permitted real time imaging, in the back-scattered electron mode, of crack initiation and growth and their relationship to the structural features in bone.

Nonlinear fracture mechanics analysis was used to determine $J$-based crack-resistance curves, i.e., $J_{\mathrm{R}}$ as a function of crack extension $\Delta a$, to capture the contributions from inelastic deformation and crack growth in the evaluation of toughness ${ }^{\S}$. The stress intensity at each measured crack length, $a$, was calculated by measuring the nonlinear strain-energy release rate, $J$, determined from the applied load and instantaneous crack length according to ASTM standards [38], and decomposed into its elastic and plastic contributions: $J=J_{\mathrm{el}}+J_{\mathrm{pl}}$. The elastic contribution $J_{\mathrm{el}}$ was based on linear-elastic fracture mechanics, where $J_{\mathrm{el}}=K_{\mathrm{I}}^{2} / E^{\prime}$ with $E^{\prime}=E$, Young's modulus, in plane stress and $E /\left(1-v^{2}\right)$ in plane strain, and $K_{I}$ is the linear-elastic mode I stress intensity. Using the load-line displacement measurements, the plastic component $J_{\mathrm{pl}}$ for a stationary crack in bending was calculated using the ASTM standard and is equivalent to $J_{\mathrm{pl}}=$

$\S$ Note that deformation conditions pertained to small-scale yielding (valid $K$-field dominance) and to plane strain, as $a, b, B>2.5\left(K_{\mathrm{I}} / \sigma_{\mathrm{y}}\right)^{2}$, where $\sigma_{\mathrm{y}}$ is the yield strength of the bone and $K$ is the stress intensity [38]. 
$1.9 A_{\mathrm{p}} / B b$, where $A_{\mathrm{pl}}$ is the plastic area under the load-displacement curve, and $b$ is the uncracked ligament length $(W-a) . K$-based fracture toughness values were back-calculated from the $J$ measurements using the standard $J-K$ equivalence for nominally mode I fracture, specifically that $K_{\mathrm{J}}=(J E)^{1 / 2}$, using the modulus values measured with nanoindentation (as described above).

\section{Synchrotron $x$-ray computed micro-tomography}

Synchrotron x-ray computed micro-tomography $(\mathrm{SR} \mu \mathrm{T})$ was performed at beamline 8.3.2 at the Lawrence Berkeley National Laboratory's Advanced Light Source (ALS) to visualize the 3D architecture of Haversian canals and the nature of the crack path after R-curve testing (1 control and 2 BP-treated from the fracture toughness test specimens). An incident x-ray energy of $20 \mathrm{keV}$ was selected with an exposure time of $1500 \mathrm{~ms}$, and a 10X magnifying lens was used to give a final spatial resolution of $0.65 \mu \mathrm{m}$ per voxel (camera PCO-Edge from PCO AG, Kelheim, Germany). Sets of 2-D angular radiographs were first reconstructed in 3-D using filtered back-projection with the software Octopus (Octopus v8; IIC UGent, Zwijnaarde), before the ImageJ processing (Rasband, W.S., ImageJ, U.S. National Institutes of Health, Bethesda http://imagej.nih.gov/ij/) and the Avizo (VSG, Visualization Sciences Group) visualization and analysis software was used to visualize in 3-D, segment and quantify the crack path and the canal network. Through a series of binary pixel open, close and erode operations, the morphology of the bone volume was binarized. Calculations of the Haversian canal diameter were performed using a 3-D ellipsoid-fitting algorithm. The average osteonal density was derived from the ratio of the binary black pixels over the total image stack volume. The tissue mineral density (TMD) was calculated by dividing the attenuation values (or gray values) of bone voxels by the mass attenuation coefficient of bone $\left(4.001 \mathrm{~cm}^{2} / \mathrm{g}\right.$ at $\left.20 \mathrm{keV}\right)$. 
Smaller samples (matchstick-like samples with a cross-section of $0.4 \mathrm{~mm} \times 0.4 \mathrm{~mm}$ ) were also imaged at the BL13W1 micro/nanoCT beamline of the Shanghai Synchrotron Radiation Facility (SSRF) with a spatial resolution of $0.37 \mu \mathrm{m} /$ voxel (4 control and 2 BP-treated samples). A tunable monochromatic $\mathrm{x}$-ray energy of $\sim 14 \mathrm{keV}$ was used to penetrate a cylindrical bone sample. This was coupled with a 2048 x 2048 pixels with an Optique Peter CCD camera with typical exposure times $\sim 2.0 \mathrm{~s}$ per projection. In this configuration, we collected a projection every $1 / 5$ or $1 / 8$ deg between 0 and $180 \mathrm{deg}$. The 2 -D projections were reconstructed to slices of 3-D using a filtered-back-projection algorithm with the software PITRE. Data sets were segmented using the algorithm of local dynamic growth, instead of overall thresholding, using Amira 5.1 software (FEI, Hillsboro, OR).

\section{In situ tensile testing at the SAXS/WAXD beamline}

To study the effects of BPs on the intrinsic toughness of bone at the submicron lengthscales ( 10 to $100 \mathrm{~nm})$, specifically involving elastic and plastic deformation at the fibrillar and mineral scales, in situ synchrotron small-angle x-ray scattering (SAXS) and wideangle x-ray diffraction (WAXD) [39] was performed at beamlime 7.3.3 at the ALS on bone samples (8 control and 9 BP-treated) subjected to uniaxial tensile loading. SAXS was used to measure the collagen fibril's $d$-period (normally $67 \mathrm{~nm}$ ), which is a regular pattern in the fibril that results from collagen molecules being bundled together in a staggered way, creating repeating molecular gaps and overlaps. The $d$-period of the fibril acts as a molecular diffraction grating when exposed to x-rays, and as the diffraction peak moves regularly as the fibril is stretched or compressed, the peak position can be used to estimate the individual strain in the collagen fibril [40]. Similarly, WAXD measures the change in the lattice spacing of 
the crystalline hydroxyapatite (HA) mineral phase (normally $0.3 \mathrm{~nm}$ ) during loading to give an estimate of the individual strain in the mineral.

Bone samples were prepared with a low-speed diamond saw along the long bone axis of humeri, ground and polished under constant irrigation to a final dimension of approximately $200 \mu \mathrm{m}$ x $1 \mathrm{~mm}$ x $20 \mathrm{~mm}$. Sandpaper was glued at their extremities to provide gripping points for the tensile tests. Samples were wrapped in HBSS-soaked gauze for at least $12 \mathrm{~h}$ at room temperature before testing. The hydrated samples were then loaded in tension at $25^{\circ} \mathrm{C}$ with a displacement rate of $1 \mu \mathrm{m} / \mathrm{s}$ in a custom-made rig with a 5-kgf load cell (Omega, LC703-10). Using an x-ray beam size at the sample of $600 \mu \mathrm{m}$ wide by $650 \mu \mathrm{m}$ high and a beam energy of $10 \mathrm{keV}$, simultaneous SAXS/WAXD measurements were taken every $7.5 \mathrm{~s}$ ( $0.5 \mathrm{~s}$ exposure time) for a limited number of points to keep the total irradiation dose underneath the detrimental limit of $30 \mathrm{kGy}$ [41]. A high-speed Pilatus 1M detector and a Pilatus 300K-W detector were positioned at $\sim 4050$ and $\sim 150 \mathrm{~mm}$ from the sample, respectively, to collect SAXS and WAXD data.

The tissue strain was obtained by measuring the change in spacing of horizontal lines marked on the sample's surface. Images were captured with a Prosilica GX1050 CCD camera (Allied Vision) and were later analyzed using custom image analysis software utilizing the National Instruments Vision Development Module; the displacement of the lines was divided by the separation at zero load to determine the bulk tissue strain. The analysis software IGOR Pro (Wavemetrics) was used in conjunction with the custom macro NIKA (Jan Ilavsky, Argonne National Laboratory) to convert the 2-D data to 1-D. The sample-to-detector distance and beam center were calibrated using a silver behenate standard. The 2-D SAXS and WAXD data were converted to 1-D by radially integrating over a $10^{\circ}$ sector and a 20 -pixel wide sector, 
respectively oriented parallel to the direction of loading. The first-order collagen and (0002) HA peaks were found by fitting the 1-D datasets with a Gaussian function and a fourth-order polynomial. The strain in the collagen fibrils and mineral were measured as the change in position of the corresponding peak's center divided by its location at zero load.

\section{Fourier transform infrared (FTIR) spectroscopy}

FTIR spectroscopy, performed at the beamline 1.4.3 at the ALS, provides a method to characterize the variations in the quality of the collagen and HA mineral in cortical bone at the molecular levels which can lead to changes in bone stiffness and intrinsic resistance to fracture. Certain features of bone's FTIR spectrum have been correlated to the characteristics of the collagen and mineral [42-44]. In the $500-1700 \mathrm{~cm}^{-1}$ region of the infrared spectrum of cortical bone, the most intense absorbance bands correspond to the vibrations of phosphate, carbonate, and amides from collagen. Therefore, the mineral/matrix area ratio can be correlated to the integrated areas of the phosphate $\left(916-1180 \mathrm{~cm}^{-1}\right)$ to Amide I $\left(1592-1712 \mathrm{~cm}^{-1}\right)$ peaks. Additionally, the cross-link ratio characterizing the collagen maturity can be defined as the area ratio of the $1660 \mathrm{~cm}^{-1}$ mature enzymatic cross-links sub-band (i.e., pyridinoline) and the 1690 $\mathrm{cm}^{-1}$ immature enzymatic cross-links sub-band, the carbonate/phosphate area ratio (i.e., the amount of carbonate replacing the phosphate) indicating the mineral maturity linked to remodeling activity by the integrated area of the $\mathrm{v} 2$ carbonate peak $\left(840-892 \mathrm{~cm}^{-1}\right)$ to that of the phosphate (916-1180 $\mathrm{cm}^{-1}$ ), and the mineral maturity associated with crystallinity (i.e., crystal size and mineral perfection) by the ratio of the $1030 \mathrm{~cm}^{-1}$ stoichiometric apatite's sub-band and the $1020 \mathrm{~cm}^{-1}$ non-stoichiometric apatite's sub-band [42-44].

Long beam samples from treated and control cortical bone (2 control and 3 BP-treated with 2 to 4 sub-samples for each bone), left over from previous flexural testing, were dehydrated 
at room temperature in a graded series of ethanol baths $(50 \%, 70 \%, 95 \%$ and $100 \%$ for $30 \mathrm{~min}$ each) to prevent water spectrum interference. Following the manufacturer's instructions, they were then infiltrated in the embedded in Spurr's low viscosity embedding media (Electron Microscopy Sciences) mixed with a series of ethanol amounts for $2 \mathrm{~h}$ prior to being fully embedded in $100 \%$ Spurr's media and cured for $8 \mathrm{~h}$ at $70^{\circ} \mathrm{C}$. The embedded bones were sectioned in the transverse direction using a microtome equipped with a diamond knife at $2 \mu \mathrm{m}$ thickness ${ }^{* *}$ and laid on EM grids (Electron Microscopy Sciences). The principle of this technique is to shine infrared light from a synchrotron source onto the sample; molecules of the sample absorb the infrared radiation at wavelengths corresponding to their natural vibrating modes. Light absorption is recorded and transformed (Fourier algorithm) into the light absorption for each wavelength (i.e., infrared spectrum) for a wide spectral range. For the background reference and the sample data, respectively 128 and 32 scans were collected in transmission mode and coadded to obtain the spectra with a data resolution of $4 \mathrm{~cm}^{-1}$ and a spot size of approximately 3 to $10 \mu \mathrm{m}$ taken in the EM grid openings after positioning under IR microscope (no correction was needed for the EM grid background). The OMNIC software (Thermo Fischer) was used to acquire infrared data, subtract the embedding media spectrum and analyze the spectra. The software Peakfit (Systat Software) was also used to subtract the baseline and to separate elementary sub-bands through the analysis of second derivative and Fourier self deconvoluted spectra.

\section{Advanced glycation end-products (AGEs)}

A fluorometric assay was performed to evaluate the extent of the AGEs in (not previously mechanically tested) samples which were taken from the posterior side of the bone. A half

\footnotetext{
*** A sample thickness of 1 to $5 \mu \mathrm{m}$ is required to transmit the infrared spectrum through the sample.
} 
cross-section of the humeral midshafts (2 control and 2 BP-treated) was demineralized using EDTA and then hydrolyzed using $6 \mathrm{~N} \mathrm{HCl}\left(24 \mathrm{~h}, 110^{\circ} \mathrm{C}\right)$. The wet weights of the bones were on the order $100 \mathrm{mg}$ (range of 78-110 mg). AGEs content was determined using fluorescence readings taken at the excitation wavelength of $370 \mathrm{~nm}$ and emission wavelength of $440 \mathrm{~nm}$. These readings were standardized to a quinine-sulfate standard and then normalized to the amount of collagen present in each bone sample. The amount of collagen for each sample was determined based on the amount of hydroxyproline, the latter being determined using a chloramine-T colorimetric assay that recorded the absorbance of the hydrolysates against a commercially available hydroxyproline standard at the wavelength of $585 \mathrm{~nm}$ [45].

\section{Statistical analysis}

The normality of distribution was verified by the Shapiro-Wilk test. For the small sample sizes ( $\mathrm{N}=2$ or 3 ) used in the AGE, FTIR and toughness tests, the normality was assumed based on previous experiments conducted on the same animal model, such as ref. [22] for AGEs and in ref. [33] for FTIR, where Dunnett's test assumes normal distribution, or based on the current workto-fracture values measured by flexural tests since this is another way to determine the toughness of bone. The two-sample Student's t-test was used as a statistical test to determine whether samples in the control and BP-treated groups follow the same normal distribution (equal group means). The groups are considered to be significantly different when the probability $\mathrm{p}$-value is less than or equal to 0.05 . All data are given as mean \pm standard error in order to indicate the uncertainty around the estimate of the mean value. Coefficients of variation or "relative variability" (standard deviation divided by the mean value) are also given in Tables 1 and 2 to compare the scatter of the studied variable between the two groups. 


\section{Results}

\section{Mechanical properties}

The mechanical properties of the untreated and BP-treated bone are listed in Table 1. Although statistical significance was not achieved, the post-yield properties, specifically the work-to-fracture and strain to failure, displayed a trend to diminish in BP-treated dogs (Table 1, Fig. 1a). Compared to the control, the treated bone trended to a reduced capacity to resist fracture in terms of a $37 \%$ lower post-yield work-to-fracture $(p=0.135)$ under flexural strength tests and $31 \%$ lower $(\mathrm{p}=0.075)$ under in situ tensile tests (SAXS-WAXD experiments) (Table 1). This is consistent with studies by Allen et al. [30]. There was a lack of significant differences in the (pre-yield) elastic properties which is also consistent with the latter study [30] that was focused on the rib cortical bone of the same beagles.

The fracture mechanics-based fracture-toughness properties of the present humerus bone were also quantified by using nonlinear-elastic fracture mechanics in terms of stress-intensity $K_{\mathrm{J}^{-}}$ based crack-resistance $R$-curves (Fig. 1b). Crack-initiation toughnesses (i.e., at crack extensions, $\Delta a \rightarrow 0)$ trended to nominally identical values in both groups $(\mathrm{p}=0.48)$. Crack-growth toughnesses, characterized by the slope of the $R$-curve, were also not statistically different $(\mathrm{p}=$ 0.32). Clearly, there was no significant difference in the extrinsic toughness of the untreated and bisphosphonate-treated bone.

\section{Bone quality at microscale levels}

To further investigate the nature and interaction of the crack path with the intra-cortical microstructure at the micrometer-scale, humerus samples were examined using back-scattered scanning electron microscopy during in situ $R$-curve testing and by $3-\mathrm{D}$ synchrotron x-ray computed micro-tomography after testing, in an attempt to discern whether the BP-treatments 
caused any variations in the bone-matrix microstructure resulting in changes in the salient toughening mechanisms. The nature of the crack paths in both control and BP-treated samples is shown in Figs. 2 and 3, respectively, from in situ SEM and SR $\mu$ T images. Crack growth in this transverse orientation can be seen to be markedly deflected, specifically resulting in major changes in direction on encountering the osteons, which run along the long axis of the bone nominally perpendicular to the expected crack trajectory along the plane of maximum tensile stress. Such marked deflections are believed to result from the variation in the mineral content and stiffness of the osteonal boundaries (the cement lines); indeed, most major microcracks form within a few degrees of these interfaces. Crack deflection is an important mode of extrinsic toughening in healthy cortical bone as deviations in crack path from the plane of maximum tensile stress act to "shield" the crack tip by lowering the local driving force, e.g., the stress intensity, experienced at the crack tip; typically a $\sim 90$ degree in-plane deflection of the crack path can almost double the toughness, with out-of-plane crack twisting potentially further increasing the toughness by up to a factor of three. However, what is important about these images is that both the control and BP-treated bone display such marked crack deflections; there is no indication that the degree of crack deflection is in any way diminished in BP-treated bone.

Despite the absence of any change in crack trajectories, the 3-D x-ray computed microtomography in Fig. 3 does reveal a significant difference in the architecture of the vascular canal network in BP-treated bones as compared to control bones. In BP-treated dogs, the Haversian canal density (i.e., the number of canals per unit bone volume) is nearly half the density found in control dogs and the mean canal diameter is $26 \%$ lower than in control dogs (Table 2), with the canals more aligned along the longitudinal axis of the bone, parallel to the periosteum surface. 


\section{Bone quality at nanoscale levels}

To characterize the corresponding intrinsic toughness that originates from plasticity mechanisms at the nanoscales (10 to $100 \mathrm{~nm}$ ), high-resolution small-angle $\mathrm{x}$-ray scattering and wide-angle $\mathrm{x}$-ray diffraction (SAXS/WAXD) combined with in situ tensile tests were used to provide quantitative insight into the nature of the deformation in the collagen and mineral (Fig. 4). Uniaxial tensile stress-strain curves for the control and BP-treated bone (Fig. 4a) were essentially identical at small tissue strains $(<0.5 \%)$; however, the post-yield plastic deformation clearly can be seen to be degraded by the BP-treatment, which results in a $31 \%$ reduction in the post-yield work-to-fracture compared to control samples $(\mathrm{p}=0.075)$.

With respect to how this strain is individually partitioned by the mineralized collagen fibrils and HA mineral (Fig. 4b,c), only minimal differences were detected in the strain carried by the mineral in control and BP-treated bone; however, above macroscopic tissue strains of $\sim 0.5 \%$, the corresponding strain carried by the collagen was distinctly lower (by $\sim 0.2 \%$ ) in treated bone (Fig. 4b). This implies that the mineralized collagen fibrils in BP-treated bone cannot absorb as much energy as fibrils in control bone such that applied loads are not transferred as effectively; this effect is similar to that seen with the aging of cortical bone [19].

\section{Bone quality at molecular levels}

Because the long-term administration of BPs has been associated with molecular changes in crystal composition and homogeneity, and with the accumulation of collagen cross-links [13], we performed Fourier transform infrared (FTIR) spectroscopy with a synchrotron x-ray source to examine the bone composition at the molecular level.

Results from the FTIR spectrum analysis in Fig. 5 show a $20 \%$ increase $(p=0.065)$ in carbonate/phosphate ratio (i.e., with mineral maturation, phosphate is progressively replaced by 
carbonate in the apatite crystal) in the BP-treated bone which is consistent with an expected reduction in bone turnover and remodeling activity [44,46]; however, no significant changes were detected in the degree of mineralization (mineral/matrix area ratio), the crystallinity (mineral maturity) and the enzymatic collagen maturity (enzymatic cross-link ratio) by the threeyear BP treatments $(\mathrm{p}>0.05)$. X-ray computed micro-tomography also shows no significant differences in tissue mineral density (Table 2).

Samples analyzed for collagen cross-links due to non-enzymatic glycation (i.e., advanced glycation end products - AGEs) using molecular fluorescence assay revealed a $22 \%$ higher $(\mathrm{p}=$ 0.046) AGEs level in BP-treated group in comparison to the control group (Fig. 6).

\section{Discussion}

Although afflicting only a small percentage of individuals, the occurrence of atypical femoral fractures has been associated with long-term administration of bisphosphonate drugs, commonly used to treat osteoporosis. However, there are still no clear explanations why certain individuals are predisposed to AFFs, why BP treatments can lead to such bone fractures, and how this can be divorced from the detrimental effect of osteoporosis on bone fragility. In this study, we attempt to discern the first stages of bone reorganization and quality of cortical bone at different structural length-scales by examining the humeri of bisphosphonate-treated healthy beagles. Indeed, the high-resolution synchrotron x-ray experiments performed in this study provide a further perspective of the effect of alendronate treatment across the multiple structural levels in cortical bone.

Many of the effects that we observe are small, subtle at best, but our results do suggest that three-year alendronate treatments, at dose levels used to treat osteoporotic women, can affect the post-yield mechanical properties of cortical bone, specifically the energy to cause fracture 
(toughness). In contrast, the pre-yield stiffness and, to a lesser degree, the bone strength appear not to be altered by this dosing regimen of bisphosphonates in healthy dogs.

Although the reduced toughness is largely associated with the intrinsic mechanisms in terms of diminished plasticity, this can be a consequence of the interrelated effects of several mechanisms occurring at different hierarchical length-scales, where any imbalance in mechanistic behavior at one of these levels can alter the overall biomechanical function of the entire bone structure. These coupled multiscale phenomena seem to be primarily driven by the BP-induced changes in bone remodeling. The first indication of this intended effect of antiresorptive drugs is seen at the molecular scale; the carbonate-to-phosphate ratio measured by FTIR spectroscopy $(20 \%$ change, $p=0.065)$ indicates changes in the interplay of bone resorption and formation (Fig. 5c). Indeed, when the replacement of older bone with new bone is not insured by active remodeling, the effects associated with biological aging can be induced at differing length-scales, as discussed in further detail below.

\section{BPs induce loss of plasticity from the nanoscopic to the macroscopic levels}

The mineral phase in bone with its high elastic modulus contributes principally to the elastic properties, whereas the organic collagen plays the major role in the plastic properties $[47,48]$. The results of this study on canine cortical humeri bone suggest that mineral content and composition (Fig. 5a,d), tissue mineral density (Table 2) as well as the deformation of the mineral phase (Fig. 4c) do not significantly change with three years of alendronate treatments, which is reflected in our observations of only minimal differences in the pre-yield mechanical properties between the BP-treated and vehicle-treated groups (Table 1). These results are in agreement with previous studies [30-32] performed on the trabecular and cortical bone of the same dogs after three years of treatment. In terms of degree of mineralization, alendronate 
treatment is known to increase the degree of mineralization in trabecular bone as shown by previous FTIR experiments performed on tibiae of the dogs studied here [33]; however in bone tissue from mid-cortical cross-sections of the same canine or human bones [33,49], this effect is not consistently reflected, which is in agreement with our own FTIR results. Conversely, the post-yield mechanical properties that principally derive from the collagen seem to be affected by BPs. Although several measures of bone properties are not changed in BPtreated bone with respect to control, we do see a trend to reduce the bending post-yield work-tofracture of $37 \%(p=0.135)$ and the tensile post-yield work-to-fracture of $31 \%(p=0.075)$ (Table 1) indicating a loss in the capacity of the cortical bone to sustain plastic deformation. These results are consistent with both one year tibia data [22] and three year rib data [30] from this same canine experimental model.

At the nanoscale, bone acquires its mechanical properties through the cooperative contributions from mineral crystals, fibrils and extra-fibrillar matrix interfaces. External tensile loads are transferred hierarchically from the tissue to the smallest particle level: from the tissue to the mineralized collagen fibrils by shearing of the extra-fibrillar matrix which essentially "glues" the fibrils together, and from the fibrils to the mineral platelets by shearing of the interparticle collagen matrix [40]. At small strains, stiff mineralized collagen fibrils are stretched (inducing unwinding/stretching of tropocollagen molecules shown by the increase of the collagen $d$-period) and the matrix is deformed by shearing. Once yielding occurs, sliding between fibrils and the extra-fibrillar matrix as well as between mineral platelets and interparticle matrix maintains a constant fibril strain and enables large dissipative deformations associated with the breaking of cross-links [50,51]. The contributions to the intrinsic toughness 
derive mainly from such mechanisms that promote plasticity and hence ductility (i.e., increased strain to failure), primarily through sliding of collagen fibrils (i.e., fibrillar sliding).

The results of the SAXS/WAXD experiments in Fig. 4 imply that tensile load is less effectively transferred at the collagen fibril level in the BP-treated bone. Indeed, for strains in the bone tissue above $\sim 0.5 \%$, the individual strain carried by mineralized collagen fibrils in BPtreated bone becomes progressively less than that in control bone (Fig. 4b), an observation which we believe is directly related to the $22 \%$ increase $(\mathrm{p}<0.05)$ in the density of non-enzymatic AGE cross-links following BP treatments (Fig. 6), acting to limit fibrillar sliding and hence ductility. Recent studies $[21,22]$ have shown that the low turnover rate associated with BP treatments can actually induce a larger accumulation of AGEs in the organic matrix of cortical bone and more specifically in the tibial bone of animals treated with these same agents for 1 year [22] (25\% increase at clinical dose and $49 \%$ increase at high dose). Thus, one clear effect of bisphosphonates can be related to changes in the collagen environment, specifically to the relative increase in non-enzymatic collagen cross-linking, which is known to have a marked influence on mechanisms such as fibrillar sliding. The limitation of fibrillar sliding can act to diminish the extent of plastic deformation, reduce the intrinsic toughness, and hence facilitate the initiation and propagation of microcracks in the collagen matrix at a higher hierarchical level.

\section{BPs affect the intracortical microstructure}

Bone quality and resistance to fracture may also be affected at the microscopic level by extrinsic toughening mechanisms that can "shield" the crack tip thereby impeding the propagation of cracks. At the scale of $\sim 10$ to $100 \mu \mathrm{m}$, a primary source of such toughening in bone results from the deflection of the crack path due to interactions with the microstructural features [50,52]. Indeed, such deflection in crack paths around osteons can be clearly seen in the 
SEM and SR $\mu$ T images for both BP-treated and untreated bone respectively in Figs. 2 and 3. As alluded to above, similar to effects reported for diseased cortical bone, specifically due to osteogenesis imperfecta [17], we had reasoned that the more homogeneous bone-matrix structure of BP-treated bone may have suppressed this crack deflection mechanism, thereby resulting in a reduced fracture resistance and smoother fracture surfaces (typically of AFFs); however, for the BP doses and the canine humeri examined in this study, there was no evidence for this, consistent with measurements of a similar fracture-toughness resistance-curve behavior in both treated and control bone (Fig. 1b). This can be related to the fact that there is no difference in the tissue mineral density (TMD) variability (Table 2) and hence no homogenization of the bone matrix.

The tomography imaging, however, did reveal significant changes in the complex microstructure of the bone that would be expected to affect the fracture toughness. As illustrated in Fig. 3, the lower rate of bone turnover associated with BPs decreased the osteonal density by $44 \%$ and reduced the Haversian canal diameter by $26 \%$. In cortical bone, the Haversian canals provide the main intracortical surface for remodeling. Consequently, the vascular canals are very likely to be partially filled with bone formation during the first three to six months of treatment when osteoclast activity is drastically slowed down but the osteoblasts are still very active. This effect has been reported for the cortical bone of osteoporotic women with reduced intra-cortical porosity after five years of treatment with risedronate [53]. Milovanovic and coworkers have recently also shown a decreased Haversian canal density in femoral bone from women treated for six years with alendronate [54,49]. At higher alendronate doses $(1.0$ $\mathrm{mg} / \mathrm{kg} / \mathrm{day}$ ), a reduction in the osteon size was identified as a result of the reduced osteoclast 
lifespan [55]. Therefore, it is likely that the reduced bone turnover initially leads to the reduction in the canal size and density as long as bone formation is active [14,54].

\section{Cyclic-loading fracture}

Investigations of the rib bones from the same dogs that were studied here also revealed that long-term (3 years) treatment with alendronate reduces fatigue life of healthy cortical bone of these animals, even though the elastic material properties from the initial cycles were not significantly different [55]. This suggests that the effects of the loss of ultrastructural plasticity and vascular changes may manifest more clearly under cyclic loading than with monotonic loading. Since atypical fractures are thought to be stress fractures occurring under daily cyclic loadings, they must be more easily revealed with cyclic loading tests. The reduction in number of cycles to failure was identified as a result of important damage propagation and accumulation in dogs treated with BPs [55], which may be related to the changes in the post-yield behavior observed here, increasing the susceptibility of microcrack accumulation and growth, and subsequently fatigue fracture. In addition, the alteration of the remodeling mechanisms will slow down the removal of damages and also contribute to microcrack accumulation.

\section{Limitations of this study}

Although the effects are not large, the current results suggest that the reduced bone turnover rate resulting from bisphosphonate treatments provides the driving force for the changes in cortical bone quality affecting collagen cross-linking at molecular scales, fibrillar plasticity at nanoscales and vascular canal size and density at microscales. However, the turnover rate in the cortical bone of dogs is known to vary between different locations; the rib cortical bone in adult beagles is approximately $18 \%$ per year whereas it is less than $1 \%$ in midshaft long bones $[30,56,57]$. For the beagle humeri investigated here, a turnover rate of $1 \% / y e a r$ or less is also 
expected. With such a low turnover rate over a three-year treatment period, the changes in the bone-matrix structure and resulting properties would be distinctly slower in comparison to untreated postmenopausal women who would have a higher porosity for bisphosphonate distribution with a turnover rate closer to 3-5\%/year [58]. It is clear that additional studies on cortical bone with a similar turnover rate and porosity to osteoporotic women would be pertinent to extrapolate the results to the human case.

This does highlight one of the weaknesses of this study, that the use of a non-osteoporotic animal model with low turnover rate and porosity might limit the extrapolation of the results to the issue of osteoporotic women; however, at the same time, it also represents a strength of this study to separate the effects of long-term BP treatments and osteoporosis. Expanding the sample size of this study (9 BP-treated humeri and 8 control humeri) would also provide enhanced statistical significance. However, as a large panel of experiments were carried out for this study, it was not always possible to test samples from every humerus bone, which further reduces the sample size. Because of the limited number of available bone samples, three of our experimental studies were conducted with small sample sizes, i.e., the AGE measurements, R-curve and FTIR tests, the latter with 2 to 4 sub-samples coming from the bone sample). Performing further studies on larger sample sizes and ideally on human femurs, would be helpful to confirm the reported effects associated with BP treatments.

\section{Conclusions}

From a perspective of seeking the possible causes of atypical femoral fractures, we investigated the role of bisphosphonate treatments in affecting the fragility of healthy cortical humerus bone. By examining humeri of bisphosphonate-treated and untreated healthy beagles, 
we identified changes in bone quality induced by three years of alendronate treatments at dose levels typical of those used to treat osteoporotic women. Our results show effects that are not large, specifically that reduced remodeling associated with bisphosphonate is primarily degrading the post-yield mechanical properties of cortical bone, in particular the energy to cause fracture. Since bone derives its toughness from its hierarchical structure spanning molecular to macroscopic length-scales, we examined toughness mechanisms at these length-scales through advanced synchrotron x-ray experiments. We confirmed that BP-treatments induce a loss in the capability of cortical bone to deform plastically, which originates from changes in the collagen environment. Here it was specifically associated with an increasing accumulation of nonenzymatic AGE cross-links at molecular scales which acts to restrict plasticity associated with fibrillar sliding at nanoscales; this in turn diminishes the intrinsic toughening mechanisms which resist the initiation and growth of cracks. At the microscale, we found that the low turnover rate due to BS-treatments leads to significant changes in the intracortical remodeling sites, namely the Haversian canals, by decreasing canal diameters and reducing the osteonal density.

These are the initial stages of bone reorganization and plasticity loss after three years of bisphosphonate treatments on healthy bones, likely to drive microdamage growth and accumulation under daily cyclic loading. We believe these phenomena can provide insight into the understanding the mechanisms behind atypical (fatigue-like) fracture, occurring at different hierarchical length-scales.

\section{Acknowledgements}

This work was funded by the National Institute of Health (NIH/NIDCR) under grant no. 5R01 DE015633 at the Lawrence Berkeley National Laboratory (LBNL). Additional funding was provided by National Institutes of Health grants AR047838 and AR007581 (for MRA and 
DBB), by the fellowship PBELP2_141095 from the Swiss National Science Foundation (for CA), and by the DFG-Emmy Noether program under grant no. BU 2562/2-1 (for EAZ and BB). Merck kindly provided the alendronate. This investigation utilized an animal facility constructed with support from the Research Facilities Improvement Program (grant no. C06 RR10601-01) from the National Center for Research Resources, National Institutes of Health. The authors also acknowledge the use of the x-ray synchrotron beamlines 1.4.3 (FTIR spectroscopy), 7.3.3 (SAXS/WAXD), and 8.3.2 (micro-tomography) at the Advanced Light Source (ALS) at LBNL, which are funded by the Office of Science of the U.S. Department of Energy under contract no. DE-AC02-05CH11231. In this regard, we would particularly like to thank Dr. D. L. Parkinson at beamline 8.3.2 for his invaluable help.

\section{References}

[1] Griffiths GR. Bone density around endosseous implants in patients taking alendronate: a pilot study. Int J Periodontics Restorative Dent. 2012;32(3):e101-08.

[2] Russell RGG. Bisphosphonates: the first 40 years. Bone. 2011;49(1):2-19.

[3] Odvina C V, Zerwekh JE, Rao DS, Maalouf N, Gottschalk FA, Pak CYC. Severely suppressed bone turnover: a potential complication of alendronate therapy. J Clin Endocrinol Metab. Endocrine Society; 2005;90(3):1294-301.

[4] Goh S-K, Yang KY, Koh JSB, Wong MK, Chua SY, Chua DTC, et al. Subtrochanteric insufficiency fractures in patients on alendronate therapy: A caution. J Bone Joint Surg Br. 2007;89(3):349-53.

[5] Lenart BA, Lorich DG, Lane JM. Atypical fractures of the femoral diaphysis in postmenopausal women taking alendronate. N Engl J Med. 2008;358(12):1304-06.

[6] Shane E, Burr D, Ebeling PR, Abrahamsen B, Adler RA, Brown TD, et al. Atypical subtrochanteric and diaphyseal femoral fractures: Report of a task force of the American Society for Bone and Mineral Research. J Bone Miner Res. 2010;25(11):2267-94.

[7] Marx RE. Pamidronate (Aredia) and zoledronate (Zometa) induced avascular necrosis of the jaws: a growing epidemic. J Oral Maxillofac Surg. 2003;61(9):1115-17.

[8] Green J, Czanner G, Reeves G, Watson J, Wise L, Beral V. Oral bisphosphonates and risk of cancer of oesophagus, stomach, and colorectum: Case-control analysis within a UK primary care cohort. BMJ. 2010;341(3):c4444. 
[9] Wysowski DK. Reports of esophageal cancer with oral bisphosphonate use. N Engl J Med. 2009;360(1):89-90.

[10] Schilcher J, Aspenberg P. Incidence of stress fractures of the femoral shaft in women treated with bisphosphonate. Acta Orthop. 2009;80(4):413-15.

[11] Shane E, Burr D, Abrahamsen B, Adler RA, Brown TD, Cheung AM, et al. Atypical subtrochanteric and diaphyseal femoral fractures: Second report of a task force of the American society for bone and mineral research. J Bone Miner Res. 2014;29(11):1-23.

[12] Ritchie RO. The conflicts between strength and toughness. Nat Mater. 2011;10(11):81722.

[13] Ettinger B, Burr DB, Ritchie RO. Proposed pathogenesis for atypical femoral fractures: Lessons from materials research. Bone. 2013;55(2):495-500.

[14] Milovanovic P, Zimmermann EA, Riedel C, vom Scheidt A, Herzog L, Krause M, et al. Multi-level characterization of human femoral cortices and their underlying osteocyte network reveal trends in quality of young, aged, osteoporotic and antiresorptive-treated bone. Biomaterials. 2015;45:46-55.

[15] Busse B, Bale HA, Zimmermann EA, Panganiban B, Barth HD, Carriero A, et al. Vitamin $\mathrm{D}$ deficiency induces early signs of aging in human bone, increasing the risk of fracture. Sci Transl Med. 2013;5:193ra88.

[16] Boskey AL, Spevak L, Weinstein RS. Spectroscopic markers of bone quality in alendronate-treated postmenopausal women. Osteoporos Int. 2009;20(5):793-800.

[17] Carriero A, Zimmermann EA., Paluszny A, Tang SY, Bale H, Busse B, et al. How tough is brittle bone? Investigating osteogenesis imperfecta in mouse bone. J Bone Miner Res. 2014;29:1392-401.

[18] Donnelly E, Meredith DS, Nguyen JT, Gladnick BP, Rebolledo BJ, Shaffer AD, et al. Reduced cortical bone compositional heterogeneity with bisphosphonate treatment in postmenopausal women with intertrochanteric and subtrochanteric fractures. J Bone Miner Res. 2012;27(3):672-78.

[19] Zimmermann EA, Schaible E, Bale H, Barth HD, Tang SY, Reichert P, et al. Age-related changes in the plasticity and toughness of human cortical bone at multiple length scales. Proc Natl Acad Sci U S A. 2011;108(35):14416-21.

[20] Nalla RK, Kinney JH, Ritchie RO. Mechanistic fracture criteria for the failure of human cortical bone. Nat Mater. 2003;2(3):164-68.

[21] Garnero P. The contribution of collagen crosslinks to bone strength. Bonekey Rep.; 2012;1:182.

[22] Tang SY, Allen MR, Phipps R, Burr DB, Vashishth D. Changes in non-enzymatic glycation and its association with altered mechanical properties following 1-year treatment with risedronate or alendronate. Osteoporosis Int. 2009;20(6):887-94.

[23] Koh JSB, Goh SK, Png MA, Ng ACM, Howe TS. Distribution of atypical fractures and cortical stress lesions in the femur: implications on pathophysiology. Singapore Med J. 2011;52(2):77-80. 
[24] Abrahamsen B, Eiken P, Eastell R. Subtrochanteric and diaphyseal femur fractures in patients treated with alendronate: A register-based national cohort study. J Bone Miner Res. 2009;24(6):1095-102.

[25] Black DM, Kelly MP, Genant HK, Palermo L, Eastell R, Bucci-Rechtweg C, et al. Bisphosphonates and fractures of the subtrochanteric or diaphyseal femur. N Engl J Med. 2010;362(19):1761-71.

[26] Shane E. Evolving data about subtrochanteric fractures and bisphosphonates. N Engl J Med. 2010;362(19):1825-27.

[27] Neviaser AS, Lane JM, Lenart BA, Edobor-Osula F, Lorich DG. Low-energy femoral shaft fractures associated with alendronate use. J Orthop Trauma. 2008;22(5):346-50.

[28] Allen MR, Burr DB. Bisphosphonate effects on bone turnover, microdamage, and mechanical properties: What we think we know and what we know that we don't know. Bone. 2011;49(1):56-65.

[29] Nalla RK, Kruzic JJ, Kinney JH, Ritchie RO. Aspects of in vitro fatigue in human cortical bone: time and cycle dependent crack growth. Biomaterials. 2005;26(14):2183-95.

[30] Allen MR, Reinwald S, Burr DB. Alendronate reduces bone toughness of ribs without significantly increasing microdamage accumulation in dogs following 3 years of daily treatment. Calcif Tissue Int. 2008;82(5):354-60.

[31] Allen MR, Burr DB. Three years of alendronate treatment results in similar levels of vertebral microdamage as after one year of treatment. $J$ Bone Miner Res. 2007;22(11):1759-65.

[32] Burr DB, Diab T, Koivunemi A, Koivunemi M, Allen MR. Effects of 1 to 3 years' treatment with alendronate on mechanical properties of the femoral shaft in a canine model: implications for subtrochanteric femoral fracture risk. J Orthop Res. 2009;27:1288-92.

[33] Gourion-Arsiquaud S, Allen MR, Burr DB, Vashishth D, Tang SY, Boskey AL. Bisphosphonate treatment modifies canine bone mineral and matrix properties and their heterogeneity. Bone. 2010;46(3):666-72.

[34] Kemp TJ, Bachus KN, Nairn JA and Carrier DR. Functional trade-offs in the limb bones of dogs selected for running versus fighting. The Journal of Experimental Biology 2005;208:3475-3482.

[35] ASTM D790-10, Standard test methods for flexural properties of unreinforced and reinforced plastics and electrical insulating materials. West Conshohocken, PA: American Society for Testing and Materials; 2010.

[36] Wang X, Allen MR, Burr DB, Lavernia EJ, Jeremic B, Fyhrie DP. Identification of material parameters based on Mohr-Coulomb failure criterion for bisphosphonate treated canine vertebral cancellous bone. Bone 2008;43(4):775-780.

[37] Oliver WC, Pharr GM. Measurement of hardness and elastic modulus by instrumented indentation: Advances in understanding and refinements to methodology. J Mater Res. 2004;19(1):3-20. 
[38] ASTM E1820-13 Standard test method for measurement of fracture toughness. West Conshohocken, PA: American Society for Testing and Materials; 2013.

[39] Hexemer A, Bras W, Glossinger J, Schaible E, Gann E, Kirian R, et al. A SAXS/WAXS/GISAXS Beamline with Multilayer Monochromator. J Phys Conf Ser. 2010;247(1):012007.

[40] Gupta HS, Seto J, Wagermaier W, Zaslansky P, Boesecke P, Fratzl P. Cooperative deformation of mineral and collagen in bone at the nanoscale. Proc Natl Acad Sci U S A. 2006;103(47):17741-46.

[41] Barth HD, Zimmermann EA, Schaible E, Tang SY, Alliston T, Ritchie RO. Characterization of the effects of x-ray irradiation on the hierarchical structure and mechanical properties of human cortical bone. Biomaterials. 2011;32(34):8892-904.

[42] Boskey A, Mendelsohn R. Infrared analysis of bone in health and disease. J Biomed Opt. International Society for Optics and Photonics; 2005;10(3):031102.

[43] Paschalis EP, Verdelis K, Doty SB, Boskey AL, Mendelsohn R, Yamauchi M. Spectroscopic characterization of collagen cross-links in bone. J Bone Miner Res. 2001 Oct;16(10):1821-28.

[44] Figueiredo MM, Gamelas JAF, Martins AG. Characterization of bone and bone-based graft materials using FTIR spectroscopy. in Infrared Spectroscopy - Life and Biomedical Sciences (ed. T Theophile), Rijeka, Croatia,Intech. 2012, pp. 315-38.

[45] Woessner JF. The determination of hydroxyproline in tissue and protein samples containing small proportions of this imino acid. Arch Biochem Biophys. 1961;93(2):44047.

[46] Isaksson H, Turunen MJ, Rieppo L, Saarakkala S, Tamminen IS, Rieppo J, et al. Infrared spectroscopy indicates altered bone turnover and remodeling activity in renal osteodystrophy. J Bone Miner Res. 2010;25(6):1360-66.

[47] Currey JD, Pitchford JW, Baxter PD. Variability of the mechanical properties of bone, and its evolutionary consequences. J R Soc Interface. 2007;4(12):127-35.

[48] Burstein AH, Zika JM, Heiple KG, Klein L. Contribution of collagen and mineral to the elastic-plastic properties of bone. J Bone Joint Surg Am. 1975;57(7):956-61.

[49] Milovanovic P, Zimmermann EA, Riedel C, Scheidt AV, Herzog L, Krause M, et al. Multi-level characterization of human femoral cortices and their underlying osteocyte network reveal trends in quality of young, aged, osteoporotic and antiresorptive-treated bone. Biomaterials. 2015;45:46-55.

[50] Launey ME, Buehler MJ, Ritchie RO. On the mechanistic origins of toughness in bone. Annu Rev Mater Res. 2010;40:25-53.

[51] Poundarik AA, Diab T, Sroga GE, Ural A, Boskey AL, Gundberg CM, et al. Dilatational band formation in bone. Proc Natl Acad Sci U S A. 2012;109(47):19178-83.

[52] Nalla RK, Kruzic JJ, Kinney JH, Ritchie RO. Mechanistic aspects of fracture and R-curve behavior in human cortical bone. Biomaterials. 2005;26(2):217-31. 
[53] Borah B, Dufresne T, Nurre J, Phipps R, Chmielewski P, Wagner L, et al. Risedronate reduces intracortical porosity in women with osteoporosis. J Bone Miner Res. 2010;25(1):41-47.

[54] Bernhard A, Milovanovic P, Zimmermann EA, Hahn M, Djonic D, Krause M, et al. Micro-morphological properties of osteons reveal changes in cortical bone stability during aging, osteoporosis, and bisphosphonate treatment in women. Osteoporosis Int. 2013;24(10):2671-80.

[55] Bajaj D, Geissler JR, Allen MR, Burr DB, Fritton JC. The resistance of cortical bone tissue to failure under cyclic loading is reduced with alendronate. Bone. 2014;64:57-64.

[56] Pearce AI, Richards RG, Milz S, Schneider E, Pearce SG. Animal models for implant biomaterial research in bone: A review. Eur Cells Mater. 2007;13(0):1-10.

[57] Polig E, Jee WSS. Bone structural parameters, dosimetry, and relative radiation risk in the beagle skeleton. Radiat Res. 1989;120(1):83.

[58] Israel O, Lubushitzky R, Frenkel A, Iosilevsky G, Bettman L, Gips S, et al. Bone turnover in cortical and trabecular bone in normal women and in women with osteoporosis. J Nucl Med. 1994;35(7):1155-58. 
Table 1: Mechanical properties of beagle cortical bone measured $e x$ situ on HBSS-soaked samples at $25^{\circ} \mathrm{C}$ from control and alendronate-treated groups. ${ }^{1}$ (Values are listed as mean \pm standard error (coefficient of variation)).

\begin{tabular}{|c|c|c|c|c|c|}
\hline Mechanical property & & atrol group & BP-treated group & $\begin{array}{c}\% \\
\text { difference }\end{array}$ & $\mathbf{p}$ \\
\hline Elastic modulus $(\mathrm{GPa})^{(\mathrm{a})}$ & 18 & $\pm 1.3(0.18)$ & $19.1 \pm 1.5(0.19)$ & 6 & 0.572 \\
\hline Hardness (GPa) & & $\pm 0.03(0.12)$ & $0.58 \pm 0.03(0.13)$ & -4 & 0.561 \\
\hline Bending stiffness $(\mathrm{GPa})^{(\mathrm{b})}$ & 11. & $\pm 0.3(0.08)$ & $10.5 \pm 0.7(0.21)$ & -8 & 0.336 \\
\hline Yield stress (MPa) & 160 & $\pm 8.8(0.16)$ & $148 \pm 15.6(0.32)$ & -8 & 0.565 \\
\hline Ultimate stress (MPa) & 185 & $\pm 8.5(0.13)$ & $166 \pm 18.5(0.33)$ & -10 & 0.399 \\
\hline Strain to failure (\%) & 2 & $\pm 0.1(0.16)$ & $1.8 \pm 0.1(0.16)$ & -9 & 0.157 \\
\hline Bending work-to-fracture $\left(\mathbf{J} / \mathbf{m}^{2}\right)$ & 1547 & $\pm 124(0.23)$ & $1245 \pm 187(0.45)$ & -20 & 0.210 \\
\hline Bending pre-yield work-to-fract. & 801 & $\pm 72(0.25)$ & $772 \pm 113(0.44)$ & -4 & 0.836 \\
\hline Bending post-yield work-to- & 747 & $\pm 123(0.47)$ & $473 \pm 152(0.77)$ & -37 & 0.135 \\
\hline Tensile work-to-fracture $(\mathrm{J} / \mathrm{m}$ & 3498 & \pm & $2753 \pm 42$ & -21 & 0.278 \\
\hline Tensile pre-yield work-to-fract. & 1316 & $\pm 291(0.73)$ & $1239 \pm 192(0.52)$ & -6 & 0.828 \\
\hline Tensile post-yield work-to-fract. & 2182 & $\pm 255(0.39)$ & $1514 \pm 250(0.55)$ & -31 & 0.075 \\
\hline
\end{tabular}

\footnotetext{
${ }^{(a)}$ Elastic moduli were measured from nano-indentation tests averaged using treated $(N=6)$ and control $(N=6)$ samples. ${ }^{\text {(b) }}$ Other mechanical properties were determined from flexural strength tests (three-point bending tests) and in situ tensile tests (at the SAXS-WAXD beamline) of hydrated unnotched beams using $N=9$ treated and $N=8$ control samples. Flexural and tensile stress-strain curves are presented in Figs. 1a and 4a, respectively.
} 
Table 2: Morphologic parameters (Canal Diameter Ca.Dm, number of canals per slice averaged on the entire volume) and tissue mineral density (TMD) quantification for control and BP-treated samples. The coefficient of variation was determined by dividing the standard deviation by the mean value.

\begin{tabular}{lccccc}
\hline & $\begin{array}{c}\text { Ca.Dm }(\boldsymbol{\mu m}) \\
\text { Mean } \pm \text { Std Dev }\end{array}$ & $\begin{array}{c}\text { Max } \\
\text { Ca.Dm } \\
(\boldsymbol{\mu m})\end{array}$ & $\begin{array}{c}\text { Average nb } \\
\text { of canals per } \\
\text { area }\end{array}$ & $\begin{array}{c}\text { TMD }\left(\mathbf{m g} / \mathbf{c m}^{\mathbf{3}}\right) \\
\text { Mean } \pm \text { Std } \\
\text { Dev }\end{array}$ & $\begin{array}{c}\text { TMD }\left(\mathbf{m g} / \mathbf{c m}^{\mathbf{3}}\right) \\
\text { Coeff. of } \\
\text { variation }\end{array}$ \\
\hline Control & $23.1 \pm 10.9$ & 63.6 & 43 & $822 \pm 75$ & 0.091 \\
BP-treated & $17.1 \pm 6.7$ & 35.3 & 24 & $847 \pm 74$ & 0.087 \\
\% difference & -26 & -44 & -44 & 3 & -4
\end{tabular}



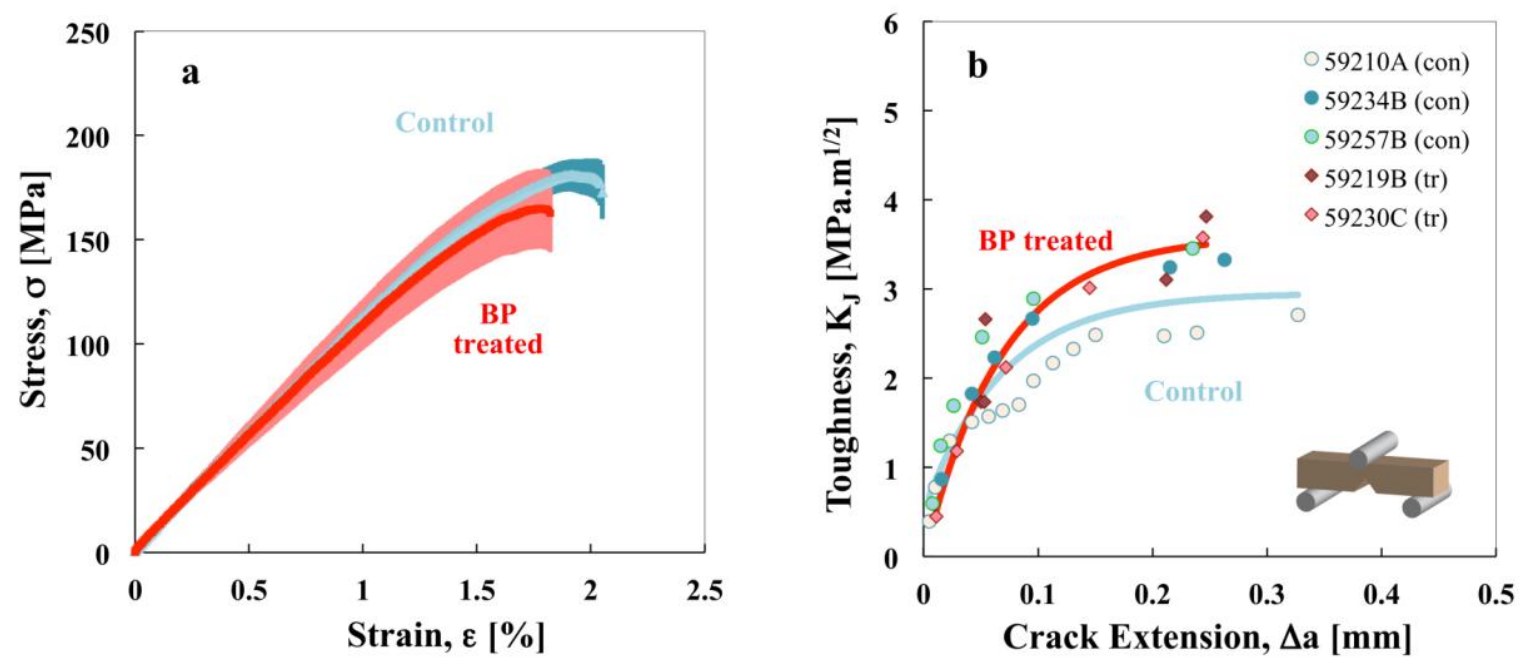

Figure 1: Flexural strength and fracture toughness tests of canine bone in the untreated (control) and bisphosphonate (BP)-treated conditions, performed in $25^{\circ} \mathrm{C} \mathrm{HBBS.} \mathrm{(a)} \mathrm{Stress-strain} \mathrm{curves}$ (mean +/- standard error, the latter shown in the shading) over 9 treated and 8 control samples and (b) representative fracture-toughness crack-resistance curves or $R$-curves over 2 treated and 3 control samples. The $R$-curves were measured in terms of the (equivalent) stress-intensity, $K_{\mathrm{J}}$, calculated using nonlinear elastic ( $J$-based) fracture mechanics. (The fracture toughness, $K_{\mathrm{J}}$, values of $3.5 \mathrm{MPa} . \mathrm{m}^{1 / 2}$ of the tested BP-treated samples represents the validity limitation for plane-strain conditions in terms of sample size.) 


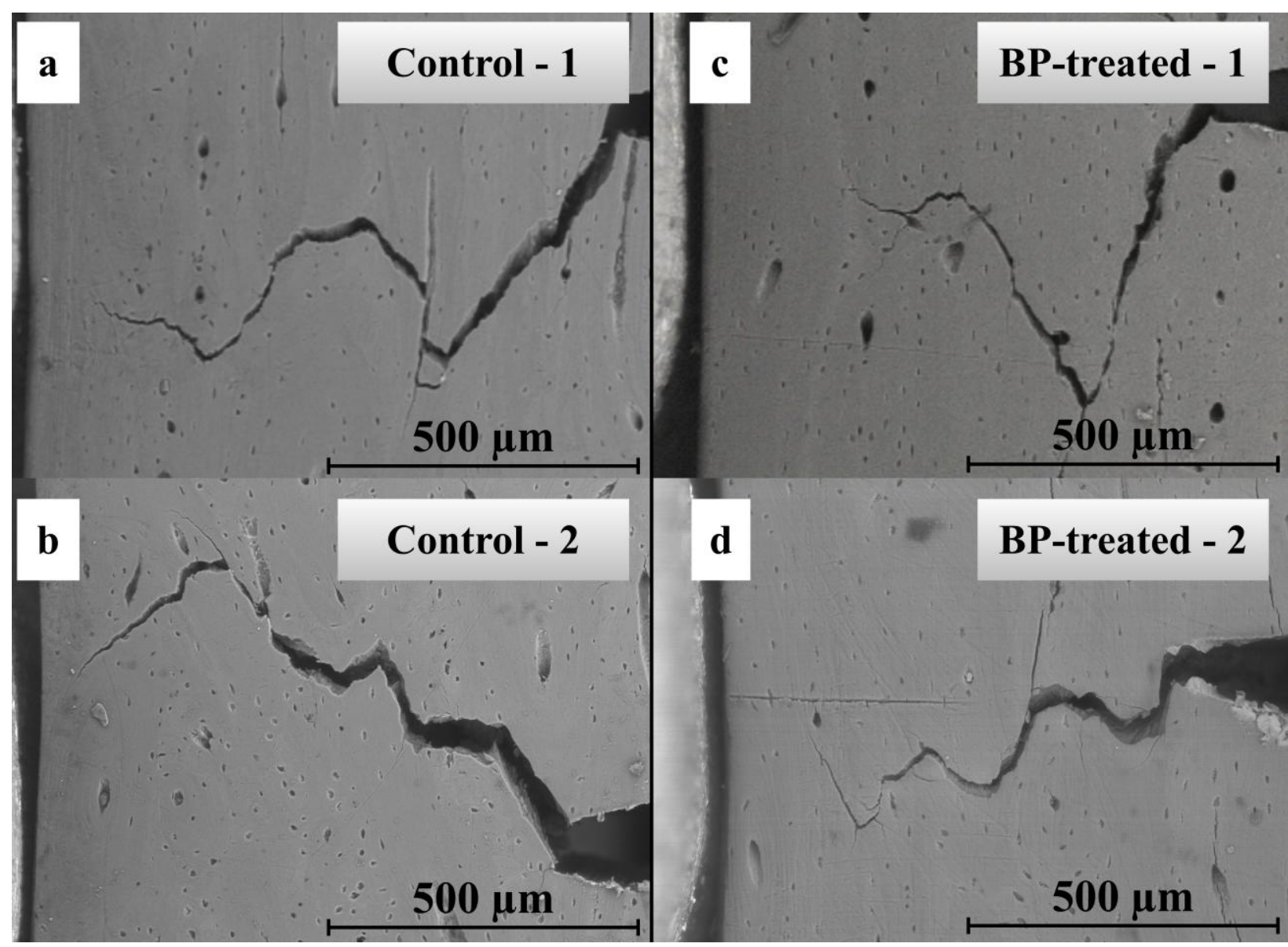

Figure 2: 2-D SEM images of the crack progression during in situ $R$-curve testing. All micronotched samples of the $(\mathrm{a}, \mathrm{b})$ control and $(\mathrm{c}, \mathrm{d})$ BP-treated cortical bone shows significant crack deviations and deflections especially as the crack encounters the osteons (results from two separate samples are shown.) Crack growth here (from right to left) is in the transverse orientation with the bone loaded longitudinally along its long axis. 

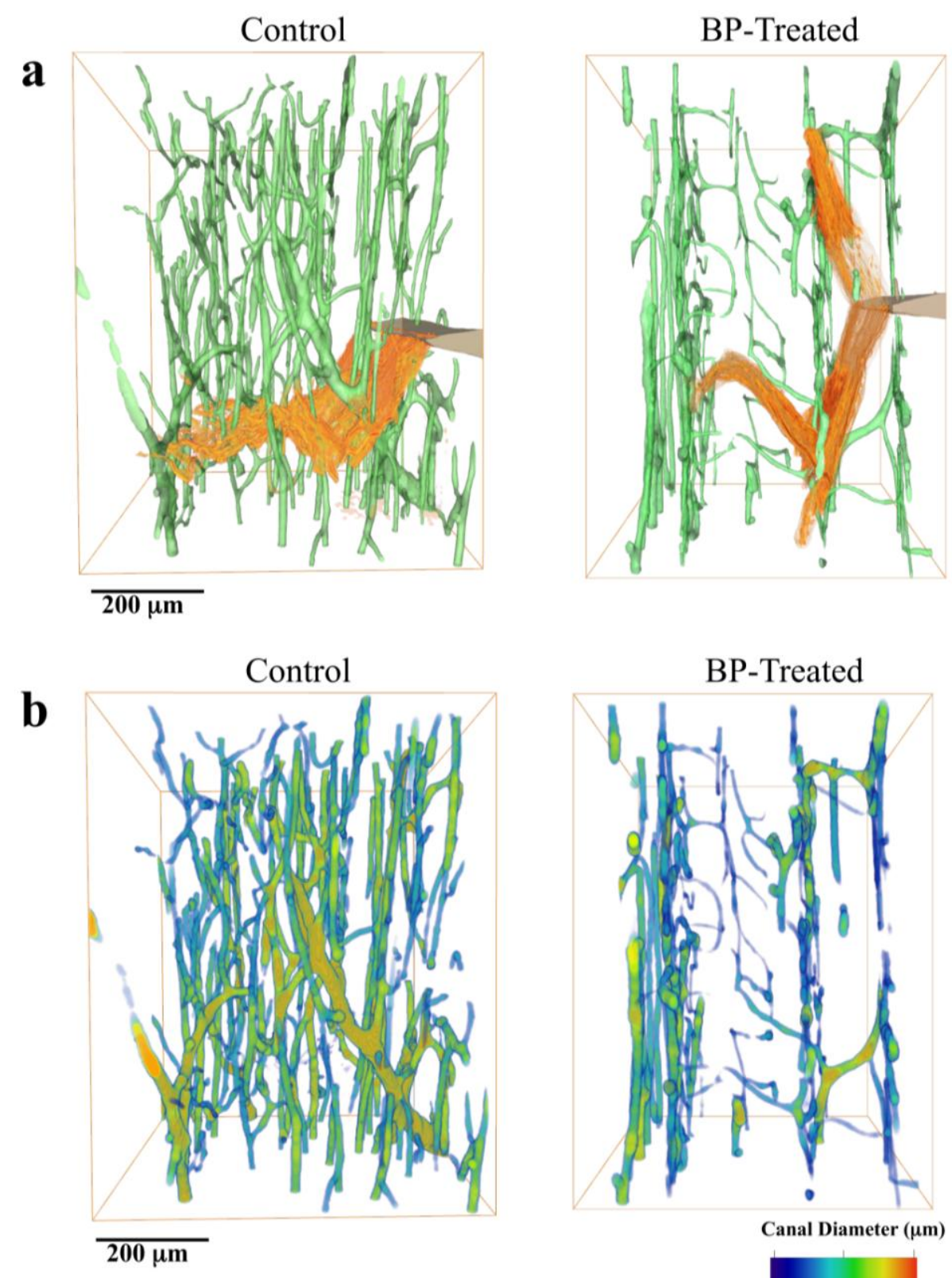

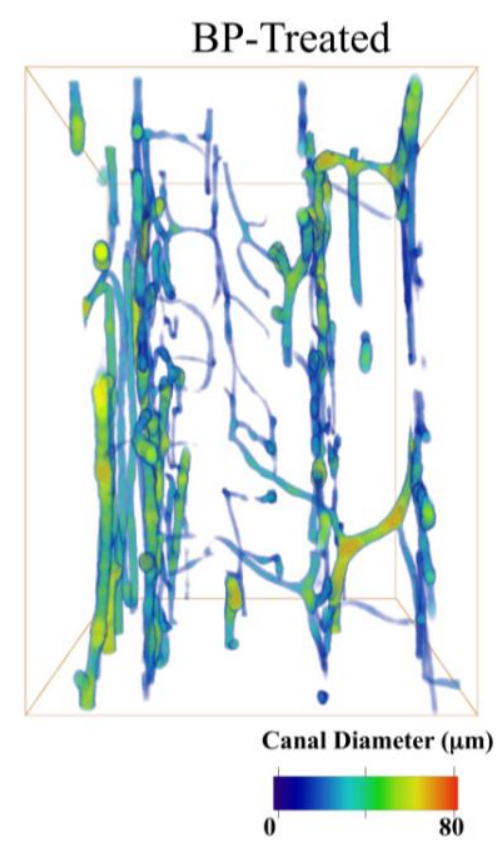

Figure 3: Synchrotron x-ray computed micro-tomography images of untreated (control) and BP-treated cortical bone. Upper images (a) show the 3-D crack profiles (from the $R$-curve testing in the transverse orientation); lower images (b) the vascular canal network. (a) In the BP-treated bone, the canals are aligned in longitudinal planes and crack surfaces are smoother in-between these planes but the deflection angles are more accentuated than in the control bone. However, both BP-treated and control bone show marked evidence of crack defection as the crack encounters the osteonal structures. (b) Images show a decrease in the Haversian canal density and of the canal diameter (the color scale indicates the diameter in $\mu \mathrm{m}$ ) in the BP-treated bone. 

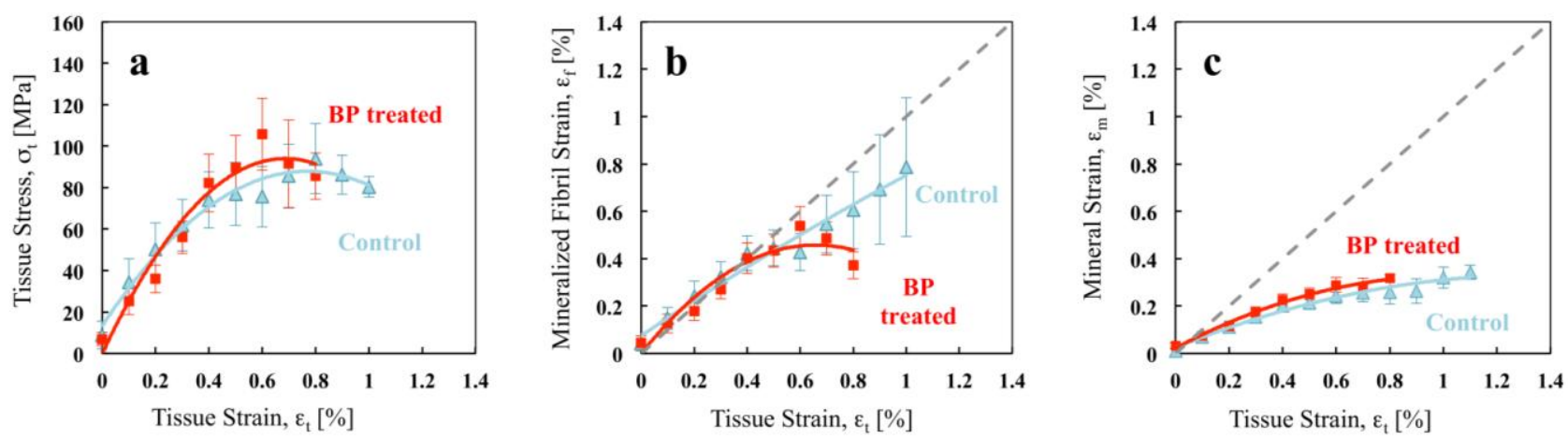

Figure 4: Results of the synchrotron SAXS/WAXD analysis on in situ tensile test experiments on 8 control and 9 BP-treated cortical bone samples. (a) Uniaxial tensile (stress/strain) curves showing the strains measured in the bone tissue and compared with strains measured in (b) the mineralized collagen fibril (stagger in the gap zone) using SAXS and (c) the HA mineral crystalline lattice using WAXD experiments. Strain values were binned every $0.1 \%$ tissue strain; when more than one data point was available, the average value of these points were calculated and plotted along with standard error bars. 

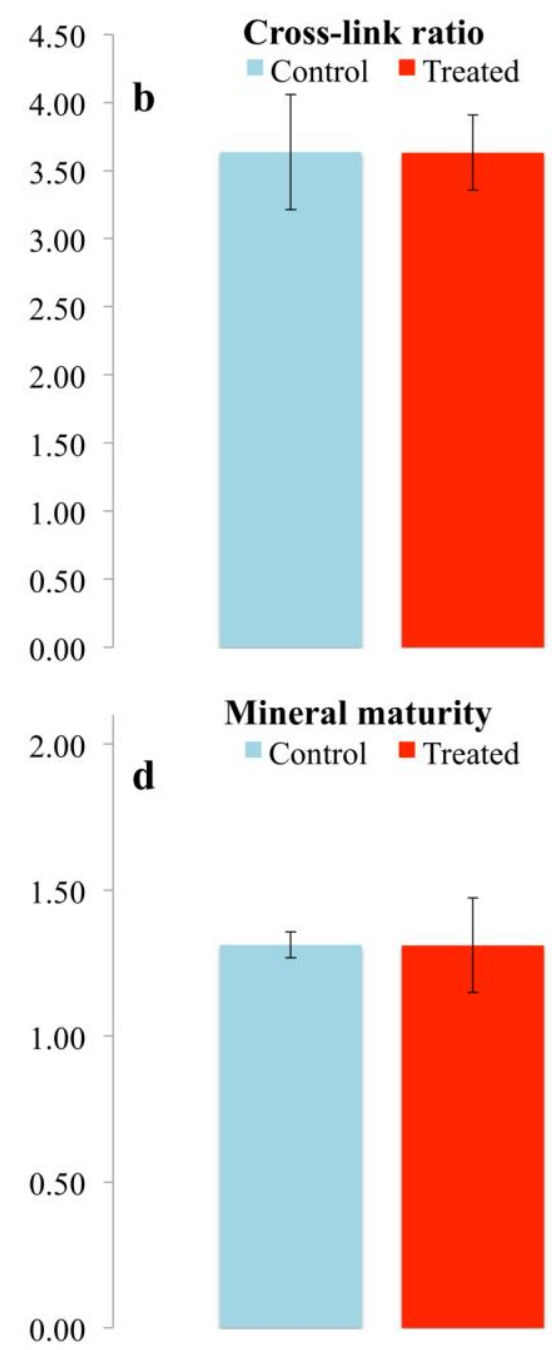

Figure 5: Bone composition measured by FTIR spectroscopy on several test pieces from 2 control and 3 BP-treated cortical bone samples (with 2 to 4 sub-samples tested for each bone sample), showing (a) the mineral/matrix area ratio (i.e., the proportion between the mineral and organic content) $(\mathrm{p}=0.933)$, (b) the cross-link ratio characterizing the collagen maturity in terms of the ratio of the mature (i.e., pyridinoline) to immature enzymatic cross-links ( $p=0.954)$, (c) the carbonate/phosphate area ratio $(\mathrm{p}=0.065)$ and $(\mathrm{d})$ the mineral maturity associated with crystallinity (i.e., crystal size and mineral perfection) $(\mathrm{p}=0.892)$. The effect of BP treatments can be seen to increase the amount of carbonate content $(\mathrm{p}=0.065)$, which replaces the phosphate phase, which is an indication of a reduction in remodeling activity. Values are given as mean $+/$ - standard error. 


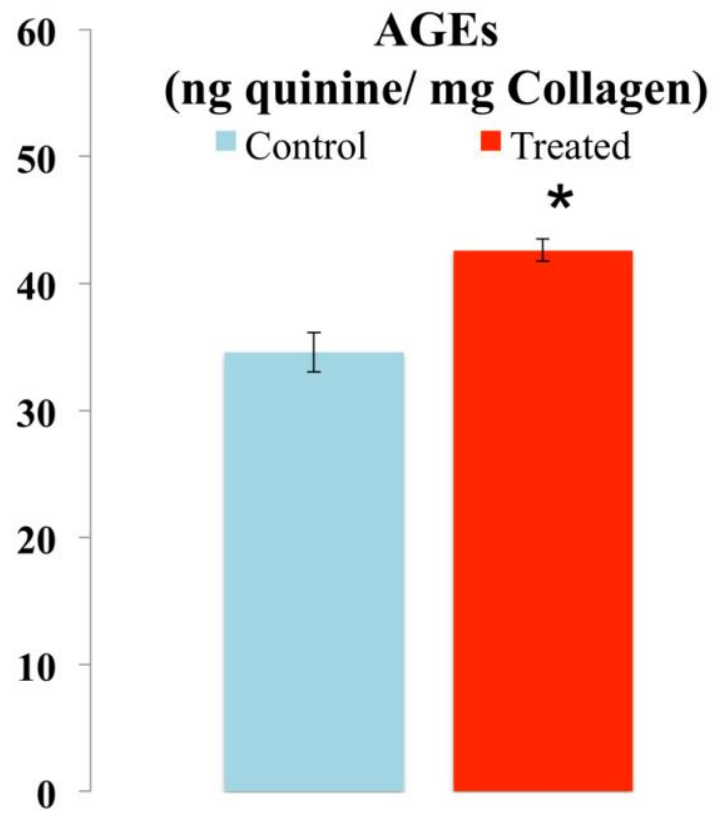

Figure 6: Results of a fluorometric assay to evaluate the extent of non-enzymatic collagen cross-links (advanced glycation end products, AGEs) in humeral midshafts bone samples of 2 untreated (control) and 2 BP-treated cortical bones. Results (mean $+/$ - standard error) show that the accumulation of AGEs is $22 \%$ higher in BP-treated samples as compared to control samples (asterisk indicates that the two populations show a difference that is statistically significant; $\mathrm{p}=$ 0.046). 